\title{
Effects of Kinesiotaping on Handgrip Isometric Strength in Athletes
}

\section{Abstract}

Purpose: To measure the acute effects of Kinesio Taping (KT) on handgrip maximal isometric strength (MIS) and strength endurance (SE) in healthy athletes.

Methods: Experimental study with repeated measures and randomization. 37 healthy men, in which 19 play racquet sports and 18 were Brazilian jiu-jitsu (BJJ) athletes. The subjects were submitted to three distinct taping conditions for the variables measurement.
i. No taping application (GSB)
ii. KT Application (GKT)
iii. Placebo Taping Application (GBP)

The variables MIS and SE were evaluated after the three conditions with JAMAR ${ }^{\circ}$ handgrip dynamometer.

Findings: No significant differences were found for the MIS ( $\mathrm{p}=.38)$ and $\mathrm{SE}(\mathrm{p}=.72)$ among the intervention arrangements. However, the BJJ athletes showed higher strength endurance than the racquet sports athletes $(\mathrm{p}=.02)$.

Conclusion: The KT applied with $25 \%$ of tension was not superior to the placebo taping application or control condition for acute assessment of MIS and SE.
Volume 2 Issue I - 2017

\author{
Marcos Atrib Zanchet,' Angel Caroline \\ Chirivino Antunes da Rocha, ${ }^{2}$ Fabrício \\ Boscolo Del Vecchio ${ }^{3}$ \\ 'Master's Student in Physical Educational, Federal University of \\ Pelotas, Brazil \\ ${ }^{2}$ Student in Physiotherapy, Catholic University of Pelotas, Brazil \\ ${ }^{3}$ Doctor in Sports Sciences University of Campinas, Federal \\ University of Pelotas, Brazil
}

Correspondence: Fabrício Boscolo Del Vecchio, Doctor
in Sports Sciences by the University of Campinas, Federal
University of Pelotas, Tel 555332732752 \& 55533273385 I, Email fabricio_boscolo@uol.com.br

Received: July 24, 2017 | Published: November 07, 2017

Keywords: hand strength, kinesio taping, muscular strength

\section{Introduction}

The Kinesio Taping (KT) is an elastic taping developed in the 70s by Kase, in Japan and it has become a popular resource in the sports world among training and rehabilitation professionals. ${ }^{1,2}$ The KT was projected with the purpose of imitating the human skin qualities, with its main characteristic the elastic composition, which makes it different from the traditional adhesive tapes. ${ }^{3,4}$ According to Wallis, $\mathrm{Kase}^{5}$ it is possible to obtain some benefits from its application, as an improvement in blood and lymphatic circulation, reduction of pain and potentiation or inhibition of muscle contraction/strength. ${ }^{5}$ Despite the KT being widely used, even in high level sport practice, little has been investigated concerning its action, and the evidence on its effectiveness is scarce. ${ }^{4,6}$ Concerning the KT capacity to change the muscle strength, some authors suggest a positive effect of the taping on the strength increment. ${ }^{7-9}$ However, other studies showed that the taping is not able to affect this variable acutely. ${ }^{10-12}$

The neuromuscular capacity to generate, grade and vary the strength is fundamental to form coordinating patterns of the movement ${ }^{13}$ and it is a basic requirement for sports performance. Certain modalities, such as combat sports and racquet sports, demand successive handgrip movements and contractions to reach success during the competitions. ${ }^{14,15}$ Therefore, adequate muscle strength and endurance are needed to perform and keep this specific movement efficiently. ${ }^{16,17}$ Thus, the purpose of this study was to measure the KT acute effects on the handgrip maximum isometric strength (MIS) and strength endurance (SE) in healthy subjects who practice Brazilian jiu-jitsu or racquet sports.

\section{Materials and methods}

\section{Type of study and variables characterization}

The study has an experimental design with randomization and repeated measures. The taping conditions were considered as independent variables and, as dependent variables, were pointed handgrip maximum isometric strength (MIS, in $\mathrm{KgF}$ ) and strength endurance (SE, in seconds).

\section{Subjects}

In order to determine the number of people involved in the study, the sample size calculation was made with the statistic software G*Power (v.3.1.2, Universität Kiel, Alemanha), considering the Mohammadi et al. ${ }^{7}$ data. The authors registered values of $38.3 \pm 6.5$ $\mathrm{KgF}$ in the handgrip maximum strength in the pre-intervention and an application of $42.4 \pm 7.3 \mathrm{KgF}$ after the Kinesio Taping use. Then, assuming a power of $90 \%$, effect size of 0.8 and significance level of $5 \%$, at least 15 men would be necessary to perform the study in each group. However, respecting the following inclusion criteria: i) age between 18 and 35 years old, ii) to practice the sport activity in which the handgrip maximum isometric force is a relevant for the performance for over two years, iii) regularly practicing it at least twice a week and iv) absence of injuries in the dominant upper limb in the twelve months before the evaluations, 37 men were eligible. Among these, nineteen practiced racquet sports ( 15 tennis players and four Padel players aging between 18 and 31 ( $24 \pm 4.4$ years), 178.1 \pm 7.5 $\mathrm{cm}$ height, $77.5 \pm 8.7 \mathrm{~kg}$ body weight, with $11.8 \pm 4.4$ years of practice of the sport and a weekly frequency of $3.5 \pm 1.7$ days/week) and 
eighteen were Brazilian jiu-jitsu (BJJ) players (aging between 18 and 35 (18.1 \pm 4.4 years) $174.1 \pm 6.5 \mathrm{~cm}$ height, $76.9 \pm 9.5 \mathrm{~kg}$ body weight with $5.4 \pm 3.3$ years of practice of the sport and a weekly frequency of 5.7 \pm 0.9 days/week). Concerning the ethical procedures, the study respected the resolution 196/96 from the Health National Council. All participants signed a free and informed consent term and the research was approved by the local Research Ethics Committee under the protocol 008/2011.

\section{Study design}

To conduct the study and to measure the variables, the athletes were met at their practice place and the evaluation of handgrip maximum isometric strength and strength endurance occurred in three distinct conditions. The subjects were randomly allocated in three groups: no KT application (NKT) placebo taping (PLA) and KT applied on the wrist flexor muscle (KTG). The individuals performed the three conditions, with an interval of, at least, one week between them (Figure 1).

The tape used for the conditions KTG and PLA was Kinesio Tex Tape ${ }^{\circledR}$ (Kinesio Holding Company, Albuquerque, NM) of black color (Figure $2 \&$ panel A). In the KTG group, the taping was applied in the "I" shape from the Epicondylus medialis humeri to the wrist joint of each subject with the flexor muscles in streched position and tension of $25 \%$ in the bandage (Figure $2 \&$ panel B). The PLA group received the application of the same type of tape, although, without a therapeutic purpose consisting of an "I" shape with $10 \mathrm{~cm}$ of length and with no tension, applied transversely to the forearm muscles close to the Epicondylus medialis humeri (Figure $2 \&$ panel C).
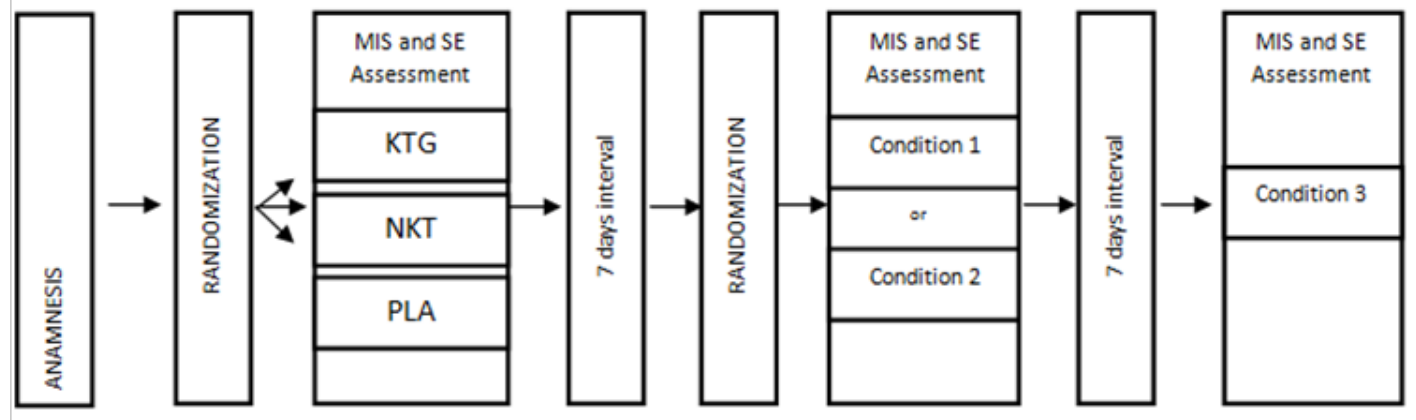

Figure I Intervention experimental design: MIS, maximal isometric strength; SE, strength endurance; NKT, no taping group; KTG, kinesio taping group; PLA, placebo taping group.

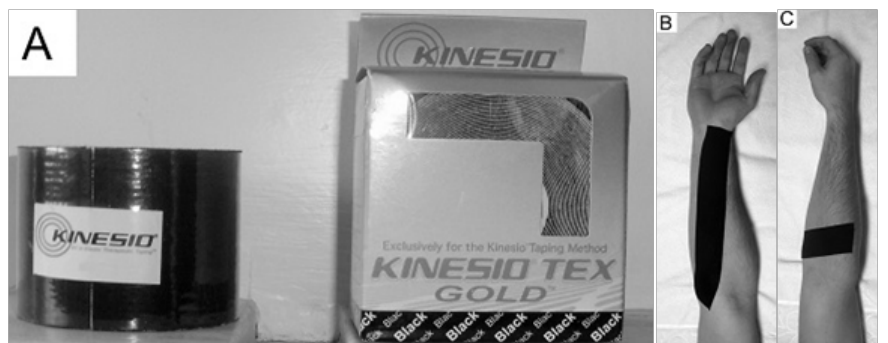

Figure 2 Kinesio taping applied in the present investigation and application modes. Panel A) type of bandage used; Panel B) Kinesio taping group; Panel C) placebo bandage group.

Data collection: To data collection, the visits were previously scheduled and the athletes should be at rest for, at least, $24 \mathrm{~h}$ from their last training session. First, the demographic data were collected, which were registered in a specific form.

The measurement of strength levels occurred with JAMAR ${ }^{\mathrm{TM}}$ (Sammons Preston, EUA) handgrip dynamometer. In this context measurements of two handgrip strength manifestations were performed:

i. Maximum isometric strength (MIS)

ii. Strength endurance (SE)

The evaluations were performed with the subjects seated, with the elbow kept firmly against the trunk and flexed on $90^{\circ}$ and with the forearm in a neutral rotation position. ${ }^{10,18}$ To minimize the suggestible aspect, the evaluated subjects did not have visual access to the KT technique which was applied in no other moment of the study. This was performed with the use of a fabric sleeve placed in the forearm with the subject blindfolded since the bandage application in order not to allow the recognition of the procedure adopted (Figure 3).

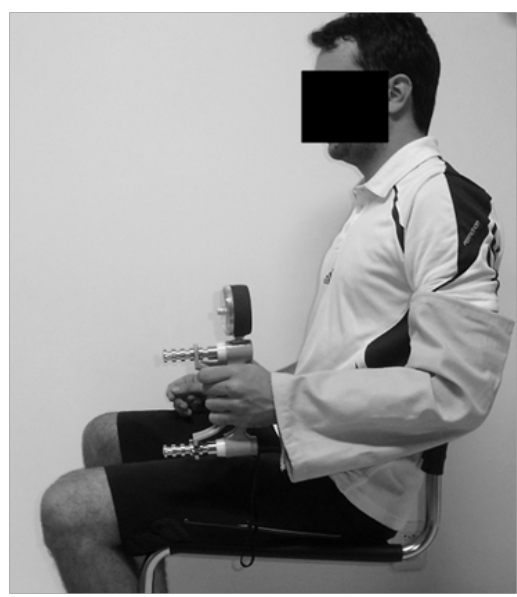

Figure 3 Test position with the fabric sleeve placed in the forearm to hinder the visual access to the $\mathrm{KT}$ technique.

Handgrip maximum isometric strength (MIS): For the MIS evaluation, the subjects pressured the dynamometer as strong as possible for 5 seconds and then liberated the hand pressure. This procedure presents high reproducibility, with an intra class correlation coefficient of $0,93 .{ }^{19}$ Three measurements were performed for each subject with interval of one minute between them, and the average was considered for the analysis. This choice took place after the Anova with repeated measures confirmed the non-statistically significant $F$ value between the trials. ${ }^{20}$ 
Strength endurance (SE): The SE evaluation occurred with the protocol proposed by Watts; Newbury; Sulentic ${ }^{21}$ which indicates a percentage of $70 \%$ of maximum strength. Thus, in a single trial the time was digitally clocked with an electronic stopwatch in which the subject managed to hold the referred force application, with a variation of 5\% above or below the MIS value calculated in each day. To control the strength amount applied in the SE test was allowed visual access to the dynamometer and verbal feedback was provided with encouragement words.

\section{Data analysis}

The data are presented as mean and standard deviation (SD). Besides that, the variation delta percentage was calculated ${ }^{22}$ between the no taping condition (NKT) and each of the situations with taping (PLA-KTG and PLA-NKT). After performing Levene's variance homogeneity test in which all the $\mathrm{p}$ values were lower than $5 \%$, were conducted the analysis of variance (ANOVA) with repeated measures to test the different evaluation moments (KTG, NKT, PLA), in which we used the Mauchly's test to check the data sphere city and the Greenhouse-Geiser correction was used when necessary. ${ }^{23}$ Identifying significance in the F-value, were used the Bonferroni's post-hoc test to identify the differences. ${ }^{24}$ In all the analysis the significance level adopted was of $5 \%$. To evaluate the magnitude of difference the power is presented with values $<0.2$ considered small, between 0.21 and 0.79 moderate and higher than 0.8 as large.

\section{Results}

Concerning the KT effects, it indicates the absence of statistical significance when compared the taping application (KTG or PLA) to the no taping condition (Table 1). The only significant difference $(\mathrm{p}=.02)$ observed is found in the strength endurance, when comparing the racquet sports and BJJ athletes. In this context, the BJJ group presented higher values with the KT application (between $40.4 \pm 15.2$ $\mathrm{s}$ and $41.6 \pm 16,5 \mathrm{~s}$ against $28.5 \pm 9.2 \mathrm{~s}$ to $29.6 \pm 10.9 \mathrm{~s}$ ), regardless of how it was applied (KTG or PLA). The Table 2 shows no significant differences in modalities and conditions in respect to the delta percentage with taping application (GKT and GBP) in relation without taping. A moderate, but non-significant difference $(\mathrm{p}=.06$, power $=.46)$ between sports type in SE test was observed.

Table I Descriptive measures and comparisons between modalities and conditions of the Kinesio Taping effects in the handgrip maximum isometric strength and in the strength endurance of racquet sports and Brazilian jiu-jitsu (BJJ) athletes

\begin{tabular}{|c|c|c|c|c|c|c|c|}
\hline & \multirow[t]{2}{*}{ Racquet(n=19) } & \multirow[t]{2}{*}{$B J J(n=\mid 8)$} & \multirow[t]{2}{*}{ All $(n=37)$} & \multicolumn{2}{|c|}{ Modalities } & \multicolumn{2}{|c|}{ Conditions } \\
\hline & & & & $\mathbf{F}$ & power & $\mathbf{F}$ & $\mathbf{p}$ \\
\hline Maximum Strength (kgf) & & & & 1.27 & 0.11 & 1.62 & 0.38 \\
\hline No Taping Group & $56.4 \pm 10.7$ & $58.2 \pm 9.3$ & $57.3 \pm 10.0$ & & & & \\
\hline Kinesio Taping Group & $58.3 \pm 13.3$ & $60.6 \pm 10.0$ & $59.4 \pm 11.7$ & & & & \\
\hline Placebo Taping Group & $59.0 \pm 11.6$ & $58.2 \pm 7.8$ & $58.6 \pm 9.8$ & & & & \\
\hline Total & $57.9 \pm 11.8$ & $59.0 \pm 9.0$ & $58.4 \pm 10.5$ & & & & \\
\hline Strength Endurance (s) & & & & 7.11 & 0.33 & 0.38 & 0.72 \\
\hline No Taping Group & $36.8 \pm 18.3$ & $39.0 \pm 16.0$ & $37.9 \pm 17.0$ & & & & \\
\hline Kinesio Taping Group* & $28.5 \pm 9.2$ & $40.4 \pm 15.2$ & $34.3 \pm 13.7$ & & & & \\
\hline Placebo Taping Group* & $29.6 \pm 10.9$ & $41.6 \pm 16,5$ & $35.4 \pm 15.0$ & & & & \\
\hline Total & $31.6 \pm 13.7$ & $40.4 \pm 15.7$ & $35.9 \pm 15.2$ & & & & \\
\hline
\end{tabular}

Table 2 Delta percentage (\%) of the Kinesio taping effects in the handgrip maximum isometric strength and in the strength endurance of racquet sports and Brazilian jiu-jitsu (BJJ) athletes

\begin{tabular}{|c|c|c|c|c|c|c|c|c|c|}
\hline & \multirow[t]{2}{*}{ Racquet(n=9) } & \multirow[t]{2}{*}{ BJJ $(n=\mid 8)$} & \multirow[t]{2}{*}{ All $(n=37)$} & \multicolumn{2}{|c|}{ Modalitis } & \multicolumn{4}{|c|}{ Condition } \\
\hline & & & & $\mathbf{F}$ & $\mathbf{p}$ & power & $\mathbf{F}$ & $\mathbf{p}$ & power \\
\hline Maximum strength (\%) & & & & 0.25 & 0.61 & 0.08 & 0.09 & 0.76 & 0.06 \\
\hline Kinesio Taping Group & $3.2 \pm 11.7$ & $4.6 \pm I I .4$ & $3.9 \pm 11.4$ & & & & & & \\
\hline Placebo Taping Group & $5.1 \pm 10.6$ & $1.1 \pm 11.3$ & $3.1 \pm 11.0$ & & & & & & \\
\hline Total & $4.1 \pm 11.0$ & $2.8 \pm 11.3$ & $3.5 \pm 11.1$ & & & & & & \\
\hline Strength endurance (\%) & & & & 3.58 & 0.06 & 0.46 & 0.1 & 0.74 & 0.06 \\
\hline Kinesio Taping Group & $-8.3 \pm 48.0$ & II. $5 \pm 40.4$ & $1.3 \pm 45.0$ & & & & & & \\
\hline Placebo Taping Group & $-5.0 \pm 44.9$ & $14.9 \pm 46.6$ & $4.7 \pm 46.2$ & & & & & & \\
\hline Total & $-6.6 \pm 45.9$ & $13.2 \pm 43.0$ & $3.0 \pm 45.3$ & & & & & & \\
\hline
\end{tabular}




\section{Discussion}

Several studies have been mentioned in the literature investigating the influence of KT on different variables, such as: pain, electromyography activity and flexibility. ${ }^{3,9,25-29}$ However, it is noticed that the relation between the KT application and the muscle strength production have presented conflicting results concerning the benefits of cutaneous stimulation provided by the taping. ${ }^{7,8,10,18}$ In the present investigation, which focused on the KT acute effects on the MIS and SE in healthy subjects who practice BJJ and racquet sports, the results did not show difference in the handgrip MIS and SE levels when different taping conditions (KT and placebo) were compared to the no taping situation. It was observed difference between the sports, with the BJJ athletes showing higher SE regardless the KT application technique. Additionally, need be pointed the large SD in delta percentage, showing higher inter-individual sensibility to KT procedure.

The fact that the KT did not influence the MIS is similar to what was reported by Chang et al. ${ }^{10}$ who did not find difference concerning the handgrip strength using the KT application on the forearm in 21 healthy men. At that time, the authors registered strength values of $53.5 \pm 7.6 \mathrm{~kg}$ for no KT condition and $54.3 \pm 6.9 \mathrm{~kg}$ for KT condition $(p=.93)$ Nevertheless, the group submitted to taping therapeutic application (in "Y" shape over the ventral forearm in the insertion to origin direction) was higher than the control condition or placebo in relation to the perception of amount of strength applied $(p<.05)$, variable which was not observed in the present investigation, and that is very subjective. The KT ineffectiveness in changing the muscle strength acutely is also described by Fu et al. ${ }^{12}$ which did not demonstrate modification in the muscle strength of 14 athletes when the taping was applied to the femoral quadriceps. Likewise, Vercelli et al. ${ }^{11}$ did not observe any KT effect on the muscle strength in lower limbs of thirty-six subjects, regardless the way the KT was applied, either for muscle stimulation (fixed in the origin towards the insertion) or muscle inhibition (placed on the insertion towards the origin).

Such results contrast with the finding of Mohammadi et al. ${ }^{7}$ who observed an increase in handgrip strength in men and women with KT application in "I" shape on the forearm. These authors monitored the changes of this variable in 40 subjects each $30 \mathrm{~min}$ during two hours and reported increase in the values of $38.33 \pm 6.5 \mathrm{~kg}$ to $42.4 \pm 7.3 \mathrm{~kg}$ $(\mathrm{p}<.05)$ in men and a change of $19.3 \pm 4.5 \mathrm{~kg}$ to $23.5 \pm 4.3 \mathrm{~kg}(\mathrm{p}<.05)$ in the women. Another study also presents a taping positive effect on the handgrip strength. Lee et al. ${ }^{18}$ compared three conditions to strength measure: control group activation of the asymmetric tonic neck reflex (ATNR) and ATNR with KT application. The authors registered an increase statistically significant in the strength values $(\mathrm{p}<.05)$ for the KT group, both in men (control:118.85 $\pm 17.99 \mathrm{lb}$, ATNR: $120.33 \pm 15.71$ $\mathrm{lb}$ and KT:125.38 $\pm 16.07 \mathrm{lb}$ ) and women (control:62.33 $\pm 11.42 \mathrm{lb}$

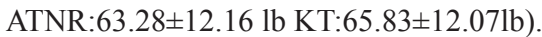

Some authors, analyzing other muscle groups and distinct populations also presented conflicting results on the muscle strength. For example Fratocchi et al. ${ }^{6}$ demonstrate a significant improvement in the concentric torque peak of the Biceps Brachii of 20 subjects (17 men) with the KT applied in "I" shape, when compared to the placebo condition. On the other hand, Wong, Cheung, $\mathrm{Li}^{30}$ did not point out any positive effect of the KT applied in "Y" shape on the Vastus Medialis in the knee iso kinetic test performance. These discrepancies between the findings may be due to the difference between the conditions of the studied populations. Some studies have healthy subjects or athletes in their samples while others present taping positive effects in individuals who present some dysfunction..$^{31,32}$ Besides that, the present investigation highlight that the methodological quality of the studies is low and few of them calculated, for example, the sample size used. In the present investigation, is reinforced the fact that all athletes were trained and healthy, with no previous injury report in the body part involved in the KT application site.

Another aspect need be mentioned. The first one is the equipment to the target variable measurement. Here, it is worth reinforce that was employed the JAMAR ${ }^{\circledR}$ dynamometer, described as the most efficient equipment for handgrip strength measuring. ${ }^{33}$ It is also noticed that the taping brand the color used range in the investigations, which may interfere in the cutaneous feedback due to the mechanical characteristics of each material. ${ }^{34}$ Even the time spent on the cutaneous stimulation with the KT varies, as the present study evaluated modifications acutely and Mohammadi et al. ${ }^{7}$ evaluated the strength fluctuations up to $2 \mathrm{~h}$ after the KT application.

Concerning the SE evaluation, only one similar study was found Schneider et al..$^{35}$ demonstrated that there is a smaller reduction of SE in tennis players who used KT in "Y" on the forearm after repeated moves. This may be attributed to the physiological mechanisms action proposed for KT, such as providing tactile stimulus through the skin and mechanoreceptors activation/inhibition ${ }^{6}$ which cause different physiological changes in the taping application place, such as an improvement in blood circulation and increase of proprioception and consequently, increase the excitability and change the muscle contraction pattern. ${ }^{8,35}$ Maybe this fact was not observed in the present investigation because of the short time of cutaneous stimulation with the KT and/or because of the low tension applied to the material in the order of $25 \%$. However such tension is indicated by Kase et al. ${ }^{5}$ as the tape tension when removed from the application paper and there are no studies so far investigating the distinct tension effects in the strength manifestation and/or SE.

Still concerning the SE the only one variable that showed some statistical difference it was possible to notice a difference between the sports practiced, in which the BJJ athletes presented a higher SE, regardless the KT application mode. Perhaps, this happened due to the specificity of the sports gesture. The BJJ purpose is throw or conduct the opponent to the ground and, after that, use positions to dominate the opponent's body in order to apply bio mechanic levers forcing their submission and the end of the combat. ${ }^{36}$ In order to do this, it is necessary to make several vigorous and sustained muscle contractions to stabilize the positions or throw down the opponent, almost always with a high handgrip strength. ${ }^{14}$ Thus it becomes necessary for these athletes to develop both maximum and endurance strength be it either general or located in upper and lower members ${ }^{16,36}$ different from the racquet sports which are characterized by intervals of handgrip use to stabilize the racquet in order to hit the ball and a brief rest until the next contact with it.

\section{Conclusion}

In the present investigation no statistically significant differences were registered in the handgrip maximum isometric strength and strength endurance after the KT use with $25 \%$ tension and applied in "I" shape on the ventral forearm. Thus, our results do not support the use of KT with the purpose of increasing muscle strength acutely in healthy athletes. 


\section{Acknowledgements}

We, MA Zanchet, AC da Rocha and, FB Del Vecchio authors of the article in titled "Kinesiotaping Effects on Maximum Isometric Strength and Strength Resistance Handgrip in Healthy Athletes" are reporting original work not previously published, in review, or in press.

\section{Conflict of interest}

The authors declare no financial support and no conflict of interest in relation to this article.

\section{References}

1. Lee JH, Yoo WG. Treatment of chronic Achilles tendon pain by Kinesio taping in an amateur badminton player. Phys Ther Sport. 2011;13(2):115119.

2. Soylu AR, Irmak R, Baltaci G. Acute effects of Kinesiotaping on muscular endurance and fatigue by using surface electromyography signals of masseter muscle. Med Sport. 2011;1(15):13-16.

3. Vera GFJ, Martínez GJ, San MR, et al. Effects of Kinesio taping on réflex of bíceps femoris and gastrocnemios lateralis. Fisioterapia. 2010;32:410 .

4. Thelen MD, Dauber JA, Stoneman PD. The Clinical Efficacy of Kinesio Tape for Shoulder Pain: A Randomized, Double-blinded, Clinical Trial. $J$ Ortop Sports Phys Ther. 2008;38(7):389-395.

5. Kase K, Wallis J, Kase T. Clinical Therapeutic Applications of the Kinesio Taping Method. 3rd ed. Japan, ken ikaico Ltd: Tóquio; 2003.

6. Fratocchi G, Di Mattia F, Rossi R, et al. Influence of Kinesio Taping applied over bíceps brachii on isokinetic elbow peak torque. A placebo controlled study in a population of Young healthy subjects. J Sci Med Sport. 2012;16(3):245-249.

7. Mohammadi K, Pouretezad M, Shokri E, et al. The effect of Forearm Kinesio Taping on Handgrip Strength of Healty People. JKMS. 2010;16(8):e19797.

8. Vithoulka I, Beneka A, Malliou P, et al. The Effects of Kinesio-Taping on quadriceps strength during isokinetic in healthy non athlete women. Isokinet Exer Sci. 2010;18:1-6.

9. Lee MH, Lee CR, Park JS, et al. Influence of Kinesio Taping on the Motor Neuron Conduction Velocity. J Phys Ther Sci. 2011;23:313-315.

10. Chang HY, Chou KY, Lin JJ, et al. Immediate effect of forearm Kinesio taping on maximal grip strength and force sense in healthy collegiate athletes. Phys Ther Sport. 2010;11(4):122-127.

11. Vercelli S, Sartorio F, Foti C, et al. Immediate Effects of Kinesiotaping on Quadriceps Muscle Strength: A Single-blinded, Placebo-controlled, Crossover trial. Clin J Sport Med. 2012;22(4):319-326.

12. Fu TC, Wong AM, Pei YC, et al. Effect of Kinesio taping on muscle strength in athletes -a pilot study. J Sci Med Sport. 2008;11:198-201.

13. Baechle T, Earle R. Essentials of Strength Training and Conditioning. 3rd ed Barueri, Manole: Brasil; 2010.

14. Oliveira M, Moreira D, Godoy J. Evaluation of the palmar grip strength in jiu-jitsu athletes in competitive level. $R$ bras Ci e Mov. 2006;14:63-70

15. Less A. Science and the major racket sports: a review. J Sport Sci. 2003;21(9):707-732.

16. Jones N, Ledford E. Strength and Conditioning for Brazilian Jiu-jitsu. Strength Cond J. 2012;34:60-69

17. Kovacs MS. Applied physiology of tennis performance. Br J Sport Med. 2006;40(5):381-386.
18. Lee J, Yoo W, Lee K. Effects of Head-neck rotation and Kinesio Taping of the Flexor Muscle on Dominant handgrip Strength. J Phys Ther Sci. 2010;22(3):285-289.

19. Brown L, Weir J. ASEP Procedures Recommendations I. Accurate assessment of muscular strength and power. $J$ Exerc Physiol. 2010;4(3):1-21.

20. Mullineaux DR, Bartlett RM, Bennett S. Research design and statistics in biomechanics and motor control. J Sport Sci. 2001;19(10):739-760.

21. Watts P, Newbury V, Sulentic J. Acute changes in handgrip strength, endurance, and blood lactate with sustained sport rock climbing. $J$ Sports MedPhys Fitness. 1996;36(4):255-260.

22. Ribeiro YS, Del Vecchio FB. Meta-analysis of the acute effects of stretching on high intensity sprint performance. Rev Bras Ed Física e Esporte. 2011;25(4):567-581.

23. Maia JA, Garganta RM, Seabra A. et al, A didactical note on the use of statistical procedures for longitudinal data. A guide for researches in Sport Sciences. Rev Port Cien Desp. 2004;4(3):115-133.

24. Field A. Discovering Statistics using IBM SPSS Statistcs. Artmed, Porto Alegre: Brasil; 2009.

25. Kalichman L, Vered E, Volchek L. Relieving Symptoms of Meralgia Paresthetica Using Kinesio Taping: A Pilot Study. Arch Phys Med Rehabil. 2010;91(7):1137-1139.

26. Hwang-Bo G, Lee JH. Effects of kinesio taping in a physical therapist with acute low back pain due to patient handling: a case report. Int $J$ Occup Med Environ Health. 2011;24(3):320-323.

27. Salvat S, Salvat A. Efectos inmediatos del kinesiotaping em La flexion lumbar. Fisioterapia. 2010;32(2):57-65.

28. Merino R, Mayorga D, Fernández E, et al. Efecto Del KinesioTaping em el rango de moviento de la cadera y zona lumbar en triatletas. Un estudio piloto. J Sport Health Res. 2010;2(2):109-118.

29. Cortesi M, Cattane D, Jonsdottir J. Effect of kinesio taping on standing balance in subjects with multiple sclerosis: A pilot study. NeuroRehabilitation. 2011;28(4):365-372.

30. Wong OM, Cheung RT, Li RC. Isokinetic knee function in healthy subjects with and without Kinesio taping. Phys Ther Sport. 2012;13(4):255-258.

31. Firth B, Dingley P, Davies ER, et al. The Effect of Kinesiotape on Function, Pain, and Motoneuronal Excitability in Healthy People and People With Achilles Tendinopathy. Clin J Sport Med. 2010;20(6):416421.

32. Paoloni M, Bernetti A, Fratocchi G, et al, Kinesio Taping applied to lumbar muscles influences clinical and electromyographic characteristics in chronic low back pain patients. Eur J Phys Rehabil Med. 2011;47:237244.

33. Moreira D, Álvarez RR, Godoy JR. Aproach about palmar prehension using dynamometer JAMAR®: a literature revision. $R$ Bras Ci e Mov. 2003;11:95-99.

34. Rodríguez JM, Durán LM, Vicén JA, et al. Vendaje neuromuscular: ¿tienen todas las vendas las mismas propiedades mecánicas? Apunts Med Sport. 2010;45(166):61-67.

35. Schneider M, Rhea M, Bay C. The Effect of Kinesio Tex Tape on Muscular Strength of the Forearm Extensors on Collegiate Tennis Athletes. Tapingbase com. 2010;1-9.

36. Del Vecchio FB, Bianchi S, Hirata SM. Morpho-functional analysis of Brazilian jiu-jitsu practitioners and time-motion analysis with motor actions quantification in the modality. Movimento \& Percepção. 2007;7:263-281. 